\title{
Mães arrependidas: literatura comercial ou crítica feminista?
}

Mães arrependidas: uma outra visão da maternidade.

DONATH, Orna. Trad. de Marina Vargas.

Rio de Janeiro: Civilização Brasileira, 2017.

\begin{abstract}
O livro Mães arrependidas: uma outra visão da maternidade (2017) causou bastante rebuliço nas redes sociais digitais quando uma entrevista da autora, Orna Donath, foi divulgada no El País (2016), assim como trechos do texto com depoimentos das mulheres que participaram da pesquisa que deu origem à publicação. Lançado em outubro de 2017 no Brasil pela Editora Civilização Brasileira, com tradução de Marina Vargas, o livro apresenta, em linguagem bastante acessível a qualquer leitor/a, depoimentos de 23 mulheres, de perfis diversificados, que afirmam ter se arrependido de terem sido mães. A partir da própria experiência como uma mulher que optou por não ter filhos, e do enunciado frequentemente dirigido às mulheres que tomam essa decisão: "você vai se arrepender de não ter tido filhos" (Orna DONATH, 2017, p. 9) é que a autora resolveu desenvolver uma pesquisa acerca de mulheres que têm filhos, mas que se arrependeram de passar por essa experiência. A pesquisa iniciou em 2008, em Israel - local onde cada mulher tem, em média, 3 filhos -, e se estendeu até 2013.

A obra se divide em 6 capítulos, mais a introdução, na qual se caracteriza o que se está entendendo por "arrependimento", é apresentado o delineamento metodológico da pesquisa e os critérios de inclusão das participantes. O primeiro elemento a ser destacado na introdução é a caracterização do arrependimento. A autora diferencia, inicialmente, da ambivalência experimentada pela maioria das mães, afirmando que confundir essas duas noções é impedir que se ouça as mulheres que de fato se arrependem. Feita essa diferença, os critérios de inclusão das participantes do estudo foram: autoidentificação das mulheres como mães arrependidas. Além da autoidentificação, para diferenciar da ambivalência, eram feitas duas perguntas às participantes: "Se você pudesse voltar atrás, com o conhecimento e a experiência que tem agora, ainda assim se tornaria mãe"? e "Do seu ponto de vista, há vantagens na maternidade?" (DONATH, 2017, p. 16). A resposta negativa a essas duas questões era critério para inclusão na pesquisa. Quando a resposta à última questão era sim, fazia-se uma última pergunta: "Na sua opinião, as vantagens superam as
\end{abstract}


desvantagens?" (DONATH, 2017, p. 16). A resposta deveria ser não. Com isso, a autora chegou às 23 participantes, que são caracterizadas ainda na introdução, constituindo uma amostra bastante diversificada: desde mulheres que têm apenas um/a filho/a, até mulheres que têm 4 filhos/as e são avós; os/as filhos/as tinham idade de 0 a 48 anos e, ainda, cinco das mulheres tinham feito uso de reprodução assistida para engravidar. 0 que chama atenção é que não se trata de mães adolescentes ou solo, a maioria tinha condições consideradas "favoráveis" para ter um/a filho/a. Nenhuma delas também era negligente, apenas 3 mulheres da amostra não viviam com os/as filhos/as.

O primeiro capítulo - "Os caminhos para a maternidade: o que a sociedade dita versus as experiências das mulheres" - explora os motivos pelos quais as mulheres se tornaram mães, discutindo a relação intrínseca materializada no binômio mulher-mãe. 0 segundo capítulo - "As exigências da maternidade: aparência, comportamento e sentimentos que as mães deveriam ter" - traz falas acerca das exigências em torno da maternidade, dos comportamentos considerados adequados, das regras e da postura emocional padrão quando se tem filhos. A autora argumenta que a divergência entre esses padrões e o real sentimento das mães explica algo em relação ao arrependimento, e não à ambivalência. O terceiro capítulo - "Mães arrependidas: se eu pudesse não ser mãe de ninguém" - apresenta relatos que aprofundam essa ideia de arrependimento, concluindo-se que o desejo dessas mulheres seria voltar a um estado de não-maternidade. O quarto capítulo - "Experiências de maternidade e práticas de arrependimento: viver com um sentimento ilícito" - apresenta relatos acerca dos conflitos oriundos pelo sentimento de arrependimento, o qual colide com o amor aos/às filhos/as, destacando-se que o arrependimento não diz respeito ao objeto filho/a, mas ao processo da maternidade. $O$ quinto capítulo - "Quem é você, mãe? As mães arrependidas entre o silêncio e o discurso" - discorre sobre o modo como as mulheres convivem e simbolizam o arrependimento, se falam sobre o assunto e com quem. Por fim, o último capítulo - "Mães-sujeitos: investigar o estado das mães por meio do arrependimento - afirma o quanto investigar sobre mães que se arrependeram é importante para compreender a própria maternidade como fenômeno complexo, vivido diferentemente por cada mulher. A autora afirma que a maternidade não deveria ser tomada como um papel, mas como uma relação humana como qualquer outra. Segundo ela, isso implicaria pensar melhores condições políticas e sociais para que as mulheres possam exercer a maternidade com mais qualidade de vida.

Orna Donath é uma antropóloga israelense de 40 anos, doutora em sociologia e pesquisadora da Universidade Ben-Gurion, de Neguev, em Beerseba, Israel, e se dedica à causa das mulheres e à pesquisa acerca dos direitos reprodutivos das mulheres e estudos de gênero. É também ativista feminista, já tendo trabalhado com mulheres em situação de violência. É autora do livro Making a Choice: Being Childfree in Israel (2011), ainda sem tradução no Brasil.

A pesquisa que resultou no livro Mães Arrependidas..., a meu ver, produziu tantos efeitos, por trazer, logo em seu título, um impossível na ordem do discurso, mesmo em meio aos debates contemporâneos em torno da maternidade: o arrependimento de mulheres que já são mães. Ainda que muitas obras clássicas já tenham discutido a não existência do instinto maternal, destacam-se nesta lista os títulos citados pela própria autora em seu livro: Um amor conquistado: o mito do amor materno, de Elisabeth Badinter (1985), e a obra de Nancy Chodorow (2002), Psicanálise da Maternidade, a pesquisa em questão inova por trazer relatos (ou seja, pesquisa empírica) daquelas que, tendo passado pela experiência de ser mãe, da qual não é possível retornar, se arrependem. Os relatos, aliás, apresentados fartamente no texto, são o diferencial da obra de Donath. O fato de juntar os elementos linguísticos: "mãe" e o adjetivo "arrependidas" materializou algo que não sabíamos, mas considerávamos 
impossível, que diz respeito ao fato de mulheres não terem sido afetadas pela "magia" da maternidade e, mesmo tendo passado pela experiência, avaliarem que teria sido melhor que isso não tivesse acontecido em suas vidas. Para mim, ainda que cause espanto, a possibilidade de dizer sobre o arrependimento da maternidade (e não dos/as filhos/as) e não colocar essas mulheres no registro da loucura ou da perversão é o grande ponto da obra de Donath. A grande contribuição, nesse sentido, é reativar o debate sobre a decisão de ser ou não ser mãe, as políticas de reprodução, trazendo para esse cenário, contraexemplos, já que a única possibilidade que se tinha até então era a de arrependimento das mulheres que não têm filhos (embora não haja, que eu saiba, nenhuma pesquisa que se volte a comprovar esse suposto arrependimento, tão disseminado no senso comum).

Que o livro é polêmico e que produziu um debate bastante incisivo nas redes sociais, não há dúvida. A dúvida para mulheres militantes e pesquisadoras é se de fato os achados de Orna Donath podem ser considerados um passo importante na pesquisa e na luta das mulheres na contemporaneidade, ou se apenas se trata de um best-seller com intuito de vender e produzir barulho em um período em que as opiniões contraditórias sobre qualquer assunto são o objeto de consumo mais valorizado. Considero que o teor do texto, a preocupação em se caracterizar o delineamento do estudo, os critérios de seleção das participantes, conceituar os elementos que são debatidos - por exemplo, o que se compreende por arrependimento - dão um caráter não apenas de cientificidade, mas de relevância dentro dos debates e questões de gênero, uma vez que coloca em pauta algo pouco discutido no campo dos estudos de gênero que é a maternidade, ainda mais quando se fala em uma experiência de maternidade perpassada pelo arrependimento. Como a autora mesmo discute, fala-se muito em mulheres-mães e mulheres não-mães, separando de forma binária esses dois grupos e homogeneizando ambos. Quando se descreve por meio de pesquisa empírica que dentro do primeiro grupo não há homogeneidade, temos um achado teórico que importa, sobretudo porque marca algo que podemos até saber, pelo senso comum, e a partir de exemplos de mães relapsas ou negligentes. As mulheres que falam na obra de Orna Donath, entretanto, são boas mães, do ponto de vista das exigências sociais, o que não garante que sejam felizes. Isso indica que devemos olhar com maior atenção para esse bloco aparentemente homogêneo que é o das mulheres-mães.

Nesse sentido, outro aspecto fundamental da obra é o fato de se chamar a atenção para a discussão de políticas públicas e condições sociais que possam melhorar as condições para as mães. E isso, segundo a autora, só é possível quando deixamos de pensar a maternidade como papel e a colocamos no campo das relações humanas. Um ponto que poderia ser melhor explorado no texto é o lugar que o patriarcado, o capitalismo e o neoliberalismo ocupam nessa seara na qual se localizam as mulheres-mães. Contudo, talvez isso tiraria o tom "leve" do texto. De modo geral, é um bom livro, que coloca em xeque muito do que circula no senso comum. Para finalizar, podemos responder à autora em pergunta feita no epílogo: "qual é o propósito de dar voz às mães arrependidas?" (DONATH, 2017 , p. 227). É apresentar a possibilidade de escolha às mulheres e lutar por melhores condições de se exercer a maternidade quando é isso que se deseja, de fato, tendo ciência das implicações inerentes a essa experiência.

\section{Referências}

BADINTER, Elisabeth. Um amor conquistado: o mito do amor materno. Trad. de Waltensir Dutra. Rio de Janeiro: Nova Fronteira, 1985.

CARBAJOSA, Ana. Orna Donath: "O instinto materno não existe". Entrevista. El País. 17/10/ 2016. Disponível em: https://brasil.elpais.com/brasil/2016/10/27/estilo/ 1477586348_982538.html. Acesso em 11/02/2018. 
CHODOROW, Nancy. Psicanálise da Maternidade. 2.ed. Trad. de Nathanael C. Caixeiro. Rio de Janeiro: Rosa dos Tempos, [1990] 2002.

DONATH, Orna. Making a Choice: Being Childfree in Israel. Tel Aviv: Miskal - Yedioth Ahronoth Books and Migdarim, Hakibbutz Hameuchad, 2011.

. Mães arrependidas: uma outra visão da maternidade. Trad. de Marina Vargas. Rio de Janeiro: Civilização Brasileira, 2017.

[Recebida em 15/02/2018

Aceita em 19/03/2018]

Kátia Alexsandra dos Santos ${ }^{1}$

'Universidade Estadual do Centro-Oeste, Departamento de Psicologia, Irati, PR, Brasil

Kátia Alexsandra dos Santos (kalexsandra@yahoo.com.br) é professora e pesquisadora da área da psicologia na Universidade Estadual do Centro-Oeste UNICENTRO, trabalhando na intersecção entre Análise de Discurso e Psicanálise. Doutora em psicologia pela Universidade de São Paulo, pesquisou em sua tese de doutorado sobre o modo como mães infanticidas são retratadas pela mídia, a partir de manchetes de notícias. Interessa-se pelos temas mulher, maternidade, discurso e mídia. Atualmente, é coordenadora do Projeto de Extensão, vinculado ao Programa Universidade Sem Fronteiras, Núcleo Maria da Penha, que realiza atendimento psicológico e jurídico a mulheres em situação de violência.

ib) 0000-0003-4706-6624.

4 Revista Estudos Feministas, Florianópolis, 26(3): e55311 